\title{
PENGARUH MEDIA AUDIO VISUAL INTERAKTIF MENGGUNAKAN PENDEKATAN CTL DALAM PEMBELAJARAN TEMATIK TERPADU TERHADAP HASIL BELAJAR DAN MOTIVASI SISWA DI SEKOLAH DASAR
}

\author{
Lisa Syupriyanti ${ }^{1}$ Firman $^{2}$, Neviyarni ${ }^{3}$ \\ Universitas Negeri Padang, Sumatera Barat, Indonesia ${ }^{1,2,3}$ \\ lisavkr@gmail.com¹,
}

\begin{abstract}
Abstrak
Tujuan - untuk membuktikan adanya pengaruh media audio visual interaktif dengan menggunakan pendekatan CTL terhadap hasil belajar siswa dalam pembelajaran tematik terpadu di kelas V SD. Metodologi - penelitian yang digunakan adalah penelitian quasi eksperimen. Sampel dalam penelitian ini ialah Kelas V SD. Teknik pengumpulan data dengan menggunakan tes. Uji hipotesis pada penelitian ini ialah dengan menggunakan rumus $t$-test. Hasil - berdasarkan perhitungan uji $\mathrm{t}\left(\mathrm{t}\right.$-test) pada post test diperoleh $\mathrm{t}_{\text {hitung }}(2,7689)>\mathrm{t}_{\text {tabel }}(1,9977)$. Hal ini berarti $\mathrm{H}_{0}$ ditolak dan $\mathrm{H}_{1}$ diterima. Implikasi - Dengan demikian dapat disimpulkan bahwa ada pengaruh positif media audio visual interaktif dengan menggunakan pendekatan CTL terhadap hasil belajar siswa dalam pembelajaran tematik terpadu di kelas V SD
\end{abstract}

Kata Kunci : Audio Visual Interaktif, CTL, Hasil Belajar

\begin{abstract}
Purpose - to prove the influence of interactive audio visual media by using the CTL approach to student learning outcomes in integrated thematic learning in class V SD. Methodology-the research used is quasi experimental research. The sample in this research is class V SD. Techniques data collection using tests. Test the Hypothesis in this study using the formula t-test. Results - based on the calculation of t test ( $t$-test) on post test obtained $t_{\text {count }}(2,7689)>t_{\text {table }}(1,9977)$. This means that $H_{0}$ is rejected and $H_{1}$ is accepted. Implementation - therefore it can be concluded there was positive influence of interactive audio visual media by using the CTL approach to student learning outcomes in integrated thematic learning in class V SD
\end{abstract}

Keywords : Audio Visual Interaktif, CTL, Learning Outcomes

@Edukasi: Jurnal Ilmu Pendidikan FIP UPTT 2019

$\triangle$ Corresponding author :

Address : Padang, Sumatera Barat

Email : 1 lisavkr@gmail.com

Phone : 085263867726

ISSN 2656-8063 (Media Cetak)

ISSN 2656-8071 (Media Online) 


\section{PENDAHULUAN}

Pembelajaran tematik terpadu adalah suatu proses pembelajaran yang menghubungkan beberapa muatan pelajaran menjadi sebuah tema. Melalui pembelajaran ini siswa dapat aktif dan terlibat pada proses pembelajaran. Pembelajaran tematik terpadu ialah proses belajar mengajar yang menekankan siswa agar terlibat pada proses pembelajaran untuk mendapatkan pengalaman langsung serta menemukan dan menggali pengetahuan yang dipelajari (Hosnan, 2014:264). Pembelajaran tematik terpadu bertujuan untuk memberikan pemahaman kepada siswa untuk mengenal, memahami berbagai pembahasan materi dan informasi yang berasal darimana dan kapan saja tidak bergantung hanya pada informasi yang diberikan guru.

Dalam pembelajaran tematik terpadu digunakan suatu pendekatan yaitu pendekatan Contextual Teaching and Learning. Langkahlangkah pembelajaran dengan menggunakan pendekatan Contextual Teaching and Learning ialah : pertama, konstruktivisme; kedua, Inkuiri; ketiga, Bertanya; keempat, Masyarakat belajar; kelima, Permodelan; keenam, Refleksi; ketujuh, Penilaian yang sebenarnya. Ketujuh langkah pendekatan CTL tersebut berguna untuk meningkatkan partisipasi dan keaktifan siswa dalam pembelajaran. Pembelajaran terpadu pada kurikulum 2013 diterapkan pada semua jenjang kelas di SD. Pembelajaran dilaksanakan tidak lagi terpisah antara satu mata pelajaran dengan mata pelajaran yang lainnya seperti pada kurikulum 2006. Oleh karena itu pembelajaran dilakukan dengan cara memadukan satu mata pelajaran dengan mata pelajaran yang lain dengan menggunakan tema pemadu tertentu. Pada penulisan ini fokus penelitiannya adalah pada muatan pelajaran IPS.

Pembelajaran IPS adalah suatu muatan pelajaran yang mempelajari tentang peristiwa, fakta, konsep, dan generalisasi yang berhubungan dengan masalah sosial. IPS merupakan suatu rancangan dalam pendidikan yang membahas kehidupan manusia dengan keadaan di lingkungan fisik dan sosialnya. Oleh karena itu, dalam pembelajaran IPS siswa diharapkan untuk menjadi seorang warga negara yang bertanggung jawab, demokratis dan cinta damai. Pembelajaran IPS bertujuan untuk memberi belak dan mendidik kemampuan dasar siswa untuk mengenal konsepkonsep yang berkaitan dengan kehidupan masyarakat dan lingkungan sekitarnya dalam memecahkan masalah sosial. Oleh karena itu, pembelajaran IPS dirancang untuk mengembangkan pengetahuan, pemahaman dan kemampuan analisis yang dimiliki peserta didik terhadap kondisi sosial masyarakat dalam memasuki kehidupan masyarakat yang dinamis.

Pembelajaran IPS yang dilakukan seorang guru pada proses pembelajaran hendaknya menerapkan berbagai strategi, pendekatan, model, dan metode pembelajaran yang sangat beragam dan bervariasi seperti bersifat konvensional maupun yang berbasis teknologi. Semua metode dan strategi yang digunakan bertujuan untuk tercapainya tujuan pembelajaran di dalam kelas.

\section{Perkembangan IPTEK dapat didorong} dengan melakukan perubahan pada proses belajar mengajar di dalam kelas dengan menggunakan teknologi pada proses pembelajaran. Maka dari itu 
guru sebagai validator mampu untuk mengoperasikan teknologi dan alat-alat yang terdapat di sekolah serta yang sesuai dengan perubahan zaman. Perkembangan IPTEK sangat berpengaruh pada kehidupan yang ada dimasyarakat satunya adalah banyaknya siswa SD yang dalam kehidupan sehari-harinya bermain gadget. Untuk itu dapat memanfaatkan teknologi dalam media pembelajaran agar dapat membuka minat siswa dalam pembelajaran.

Berdasarkan hasil penelitian terdahulu saat proses pembelajaran IPS terlihat pengetahuan guru untuk menggunakan teknologi masih rendah. Hal ini mengakibatkan rendahnya hasil belajar siswa karena banyaknya guru dalam melalukan proses pembelajaran bersifat konvensional, belum menggunakan teknologi sebagai media penunjang dalam proses pembelajaran di dalam kelas sehingga saat proses pembelajaran berlangsung siswa sering keluar masuk dan bercerita dengan temannya serta minat siswa dalam belajar masih kurang karena siswa terbiasa bermain game di Hp.

Motivasi merupakan faktor yang dapat mempengaruhi keefektifan pada suatu kegiatan. Motivasi dapat mendorong seorang siswa untuk melakukan kegiatan belajar mengajar. Para ahli psikologi menjelaskan bahwa motivasi merupakan proses dan dorongan yang ada dalam diri individu yang aktif, serta memberikan arah, untuk menjaga sikap dan perilaku (Slavin, 1994). Jadi motivasi belajar yaitu dorongan dari dalam maupun luar diri siswa untuk menciptakan kondisi tertentu yang mengarahkan untuk tercapainya suatu tujuan.
Kemajuan terhadap ilmu pengetahuan dan teknologi pada saat ini sangat berpengaruh terhadap penggunaan alat-alat bantu proses belajar mengajar di sekolah seperti media, bahan ajar yang merupakan cara tepat untuk menunjang pembelajaran menjadi lebih efektif dan efisien. Kemajuan teknologi membuat dampak yang signifikan dalam perkembangan metode pembelajaran yang dari tatap muka menjadi sistem pembelajaran yang berbasis komputer (e-learning). Pembelajaran di dalam kelas tidak pernah lepas dari penggunaan media pembelajaran yang menarik.

Media pembelajaran adalah alat komunikasi yang efektif dalam proses belajar mengajar untuk tercapainya tujuan pembelajaran yang ingin dicapai. Media audio visual adalah salah satu media pembelajaran yang menggabungkan komponen audio (suara) dan visual (gambar) untuk mengkomunikasikan pesan atau informasi. Media ini berisikan gambar yang dilengkapi serta ditekankan pada komponen audionya (suara). Cakupan materi yang akan digunakan ialah tentang Peran Ekonomi dalam menyejahterakan kehidupan masyarakat. Pembelajaran dengan menerapkan media audio visual interaktif bertujuan untuk memudahkan dalam proses pembelajaran, menumbuhkan kreatifitas dan inovasi pendidik dalam mendesain pembelajaran yang komunikatif dan interaktif sebagai solusi permasalahan dalam pendidikan (Daryanto, 2010:64).

Salah satu peran guru yaitu sebagai fasilitator yang berperan dalam memberikan pelayanan untuk memudahkan siswa dalam proses pembelajaran. Guru dituntut untuk memiliki kemampuan dan kreatifitas dalam menggunakan media pembelajaran yang cocok sehingga proses belajar mengajar 
menjadi lebih menarik. Salah satu program yang dapat dimanfaatkan dalam pembuatan media audio visual interaktif adalah dengan menggunakan program adobe flash. Program adobe flash merupakan program yang dapat memvisualkan dunia nyata dengan menggunakan teknologi. Kelebihan tersebut dapat diharapkan untuk mewujudkan sebuah aplikasi media pembelajaran yang akan menarik minat dan motivasi siswa dalam pembelajaran sehingga hasil belajar siswa dapat meningkat.

\section{METODOLOGI PENELITIAN}

Jenis penelitian yang digunakan adalah quasi eksperimen dengan desain non equivalen pre-test and post-test control group design. Populasi dalam penulisan ini yaitu seluruh siswa kelas V SDN Gugus IV Kecamatan Padang Utara dengan sampel seluruh peserta didik kelas V SDN 26 Air Tawar Timur yang berjumlah 29 orang dengan SDN 16 Air Tawar Timur yang berjumlah 29 orang. Pengambilan sampel yang dilakukan adalah dengan teknik non probability dengan tipe cluster random sampling yang dilakukan secara acak tanpa memerhatikan strata dalam pengambilan sampel. Teknik pengumpulan data yang digunakan pada penulisan ini yaitu teknis tes berupa soal pilihan ganda. Teknik yang digunakan untuk menganalisis hipotesis menggunakan rumus uji-t.

\section{HASIL PENELITIAN}

Data yang di deskripsikan disini merupakan data hasil pre-test dan pos-test dari kedua kelas. Data yang digunakan dalam penelitian ini berupa data kuantitatif berupa tes objektif.
Tabel 1 Rekapitulasi Hasil Pre-test Hasil Belajar Pembelajaran IPS Kelas Eksperimen dan Kelas Kontrol

\begin{tabular}{|c|c|c|}
\hline \multirow{2}{*}{ Variabel } & \multicolumn{2}{|c|}{ Pre-Test } \\
\hline \multirow{N}{*}{} & $\begin{array}{c}\text { Kelas } \\
\text { Eksperimen }\end{array}$ & $\begin{array}{c}\text { Kelas } \\
\text { Kontrol }\end{array}$ \\
\cline { 2 - 3 } & 34 & 32 \\
\hline $\begin{array}{c}\text { Nilai } \\
\text { Tertinggi }\end{array}$ & 90 & 80 \\
\hline $\begin{array}{c}\text { Nilai } \\
\text { Terendah }\end{array}$ & 10 & 10 \\
\hline Mean & 42,94 & 37,66 \\
\hline SD & 16,72 & 15,35 \\
\hline SD & 279,70 & 235,78 \\
\hline
\end{tabular}

Berdasarkan data pada kelas eksperimen dan kelas kontrol berangkat dari titik tolak yang sama. Kemudian hasil post-test untuk kelas eksperimen dan kelas kontrol dapat dilihat di bawah ini :

Tabel 2 Rekapitulasi Hasil Post-test Hasil Belajar Pembelajaran IPS Kelas Eksperimen dan Kelas Kontrol

\begin{tabular}{|c|c|c|}
\hline Variabel & \multicolumn{2}{|c|}{ Post-Test } \\
\hline \multirow{2}{*}{$\mathrm{N}$} & Kelas & Kelas \\
& Eksperimen & Kontrol \\
\cline { 2 - 3 } & 34 & 32 \\
\hline
\end{tabular}




\begin{tabular}{|c|c|c|}
\hline $\begin{array}{c}\text { Nilai } \\
\text { Tertinggi }\end{array}$ & 95 & 85 \\
\hline $\begin{array}{c}\text { Nilai } \\
\text { Terendah }\end{array}$ & 40 & 35 \\
\hline Mean & 79,26 & 73,13 \\
\hline SD & 9,54 & 8,46 \\
\hline SD $^{2}$ & 90,95 & 71,69 \\
\hline
\end{tabular}

Tabel 3 Uji Normalitas

\begin{tabular}{|c|c|c|c|c|}
\hline Kelas & $\mathbf{N}$ & $\mathbf{a}$ & $\mathbf{D}_{\text {hitung }}$ & $\mathbf{D}_{\text {tabel }}$ \\
\hline Eksperi & 3 & 0,0 & 0,18256 & 0,24 \\
men & 1 & 5 & 4 & \\
\hline Kontrol & 3 & 0,0 & 0,15986 & 0,24 \\
& 1 & 5 & 8 & \\
\hline
\end{tabular}

Berdasarkan data di atas dapat diperoleh kesimpulan bahwa kelas eksperimen maupun kelas kontrol sama-sama berdistribusi normal karena $\mathrm{D}_{\text {hitung }}<\mathrm{D}_{\text {tabel. }}$.

Teble 4. Uji normalitas post-test kelas eksperimen dan kelas kontrol

\begin{tabular}{|c|c|c|c|c|}
\hline Kelas & $\mathbf{N}$ & $\mathbf{a}$ & $\mathbf{D}_{\text {hitung }}$ & $\mathbf{D}_{\text {tabel }}$ \\
\hline Eksperi & 3 & 0,0 & 0,09722 & 0,24 \\
men & 1 & 5 & 4 & \\
\hline Kontrol & 3 & 0,0 & 0,11490 & 0,24 \\
& 1 & 5 & 5 & \\
\hline
\end{tabular}

Berdasarkan data di atas dapat disimpulkan bahwa kelas ekperimen dan kelas kontrol sama-sama berdistribusi normal karena $D_{\text {hitung }}<D_{\text {tabel. }}$.

Tabel 5. Uji Homogenitas

\begin{tabular}{|c|c|c|c|c|}
\hline Kelas & A & $\mathbf{b}_{\text {hitun }}$ & $\mathbf{b}_{\text {tabel }}$ & Keteranga \\
& & g & & $\mathbf{n}$ \\
\hline
\end{tabular}

\begin{tabular}{|l|c|c|c|l|}
\hline Eksperime & 0,0 & 1,99 & 0,938 & Homogen \\
n & 5 & 7 & 6 & \\
\hline Kontrol & 0,0 & 1,99 & 0,938 & Homogen \\
& 5 & 7 & & \\
\hline \multicolumn{5}{|c}{ Berdasarkan tabel di atas dapat }
\end{tabular}

disimpulkan bahwa hasil post-test kedua kelas tersebut berasal dari populasi yang homogen karena memenuhi kriteria $\mathrm{b}_{\text {hitung }}<\mathrm{b}_{\text {tabel }}$ (Irianto, 2008:276)

Untuk menguji suatu hipotesis digunakan uji-t (t-test). Berdasarkan hasil uji hipotesis yang didapatkan melalui t-test tersebut dapat dilihat pada tabel dibawah ini:

Tabel 6 Hasil Pengujian dengan t-test

\begin{tabular}{|c|l|c|c|c|}
\hline No & Kelas & $\begin{array}{c}\mathbf{X} \\
\text { Kelas }\end{array}$ & $\mathbf{t}_{\text {hitung }}$ & $\mathbf{t}_{\text {tabel }}$ \\
\hline 1. & $\begin{array}{l}\text { Eksperi } \\
\text { men }\end{array}$ & 79,26 & $\begin{array}{c}2,7688 \\
7441\end{array}$ & $\begin{array}{c}1,99 \\
773\end{array}$ \\
\hline 2. & Kontrol & 73,13 & & \\
\hline
\end{tabular}

Berdasarkan tabel $\mathrm{t}$ dengan $\mathrm{dk}\left(\mathrm{N}_{1}-1\right)+\left(\mathrm{N}_{2}-\right.$ 1) $=64$. Maka yang jadi pedoman pada tabel yaitu dengan dk 64 untuk taraf nyata 0,05 di dapatkan harga $t_{\text {tabel }} 1,99773$. Dengan demikian $t_{\text {hitung }}>t_{\text {tabel }}$ yaitu 2,76887441 > 1,99773. Maka dapat ditarik kesimpulan bahwa hasil belajar siswa yang mengikuti pembelajaran dengan menggunakan media audio visual interaktif berbasis adobe flash lebih tinggi dari pada hasil belajar yang tidak menggunakan media ini serta terdapat pengaruh yang positif dari hasil belajar siswa antara kelas eksperimen yang menerapkan media audio visual interaktif berbasis adobe flash dibandingkan kelas kontrol yang tanpa menggunakan media audio visual interaktif berbasis adobe flash. 


\section{Pengaruh Media Audio Visual Interaktif Menggunakan Pendekatan CTL Dalam Pembelajaran Tematik Terpadu Terhadap Hasil Belajar Dan Motivasi Siswa di Sekolah Dasar - Lisa Syupriyanti, Firman, Neviyarni}

Selama pembelajaran di kelas eksperimen, peserta didik mengerjakan LKPD secara berkelompok sebagai cara bagi peserta didik untuk menemukan pengetahuan mereka sendiri, berdasarkan gambar yang mereka amati pada media pembelajaran yang ditampilkan. Setelah selesai mengerjakan LKPD, masing-masing perwakilan kelompok mengemukakan hasil diskusinya. Hal ini bertujuan untuk mengungkapkan jawaban LKPD yang telah didapatkan dan dikerjakan secara berkelompok oleh peserta didik.

Pada penilaian ranah sikap, peserta didik diberi lembar skala sikap yang dikerjakan oleh peserta didik.

Penilaian ranah keterampilan, penulis memberi tugas kepada peserta didik untuk membuat sebuah peta konsep mengenai materi yang diajarkan. Hasil penulisan ini dapat disimpulkan media audio visual interaktif berbasis adobe flash berpengaruh positif terhadap hasil belajar dan motivasi siswa pada pembelajaran IPS di kelas V SD.

\section{SIMPULAN}

Terdapat perbedaan yang mendominasi antara hasil belajar pada kelas eksperimen yang belajar dengan menggunakan media audio visual interaktif dengan kelas kontrol yang tidak menggunakan media audio visual interaktif. Kemudian nilai rata-rata kelas eksperimen yang belajar dengan menggunakan media audio visual interaktif lebih tinggi dibandingkan dengan kelas kontrol yang tidak menggunakan media audio visual interaktif. Nilai rata-rata hasil belajar kelas eksperimen yaitu 79,26 sedangkan nilai rata-rata hasil belajar kelas kontrol yaitu 73,13. Berdasarkan analisis data di dapat hasil $t_{\text {hitung }}>t_{\text {tabel }}$ yaitu 2,7687 $>$ 1,9977. Maka dapat disimpulkan bahwa adanya pengaruh positif terhadap penerapan media audio visual interaktif berbasis adobe flash terhadap hasil belajar siswa dalam Pembelajaran IPS di kelas V SD Gugus IV Kecamatan Padang Utara.

Berdasarkan kesimpulan di atas, dapat diajukan saran yang dapat dijadikan sebagai pertimbangan yaitu : Media Audio Visual Interaktif Berbasis Adobe Flash dapat digunakan pada konsep yang karakteristiknya sama dengan contoh materi peran ekonomi dalam menyejahterakan kehidupan masyarakat.

\section{DAFTAR RUJUKAN}

Daryanto. (2010). Penelitian Tindakan Kelas dan Penelitian Tindakan Sekolah. Yogyakarta: CV Gava Media.

Hosnan. (2014). Pendekatan Scientifik dan Kontekstual Dalam Pembelajaran Abad 21 : Kunci Sukses Implementasi Kurikulum 2013. Jakarta: Ghalia Indonesia.

Irianto, A. (2015). Statistik Konsep Dasar, Aplikasi dan Pengembangannya. Jakarta: Prenadamedia Group.

Sugiyono. (2012). Metode Penelitian Pendidikan Pendekatan Kuantitatif, Kualitatif, RnD. Bandung: Alfabeta. 